\title{
STUDY OF SERUM ADIPONECTIN AND HIGH SENSITIVITY C-REACTIVE PROTEIN IN DIABETIC PATIENTS
}

\author{
SHAILZA SHRESHTHA ${ }^{1}$, PREETI SHARMA ${ }^{1 *}$, PRADEEP KUMAR ${ }^{1}$, RACHNA SHARMA ${ }^{2}$, SHIVANI GUPTA ${ }^{1}$, \\ TAPAN MAHAPATRA
}

${ }^{1}$ Department of Biochemistry, Santosh Medical College and Hospital, Ghaziabad, Uttar Pradesh, India. ${ }^{2}$ Department of Biochemistry, TSM Medical College and Hospital, Lucknow, Uttar Pradesh, India. Email: prcdri2003@yahoo.co.in

Received: 14 December 2017, Revised and Accepted: 02 April 2018

ABSTRACT

Objectives: Adiponectin, a major cytokine from adipose tissue, and high sensitivity C-reactive protein (hs-CRP), well-established markers of inflammation are known to be associated with increased risk of cardiovascular disorders (CVD). Therefore the objective of our study was to evaluate the levels of these parameters and determine their correlation with glycemia to assess the cardiovascular risks in the patients with Type 2 diabetes mellitus.

Methods: This study was conducted in the Department of Biochemistry, Santosh Medical College, Ghaziabad, with 25 Type 2 diabetic patients and 25 age and sex-matched controls. Ethical clearance from the institution and informed consent from the patients were taken before the study. Adiponectin was analyzed by enzyme-linked immunoadsorbent assay, and blood sugar and CRP were estimated by the kit based method.

Results: Fasting blood sugar (FBS, 158.2 \pm 37.2$)$ and hs-CRP $(3.97 \pm 1.54)$ were significantly high, adiponectin was significantly low in the patients with diabetes compared to controls $(80.52 \pm 9.72,1.27 \pm 0.75$, and $10.78 \pm 1.69$, respectively, $\mathrm{p}<0.05)$. Adiponectin showed a negative correlation with FBS $(\mathrm{r}=-0.427)$ and hs-CRP ( $\mathrm{r}=-0.336)$, but the correlation was significant only in case of FBS $(\mathrm{p}<0.05)$. hs-CRP positively correlated with FBS ( $\mathrm{r}=0.568)$ and was statistically significant

Conclusion: The results of our study further support the role of adiponectin and hs-CRP as a predictive biomarker of CVD risks in the patients suffering from Type 2 diabetes.

Keywords: Adiponectin, High sensitivity C-reactive protein, Diabetes mellitus, Cardiovascular disease.

(C) 2018 The Authors. Published by Innovare Academic Sciences Pvt Ltd. This is an open access article under the CC BY license (http://creativecommons. org/licenses/by/4. 0/) DOI: http://dx.doi.org/10.22159/ajpcr.2018.v11i7.24252

\section{INTRODUCTION}

Diabetes mellitus, the most common metabolic disorder featured with hyperglycemia [1], is an important area of concern worldwide due to its increasing prevalence and complications [2]. In 2011, the International Diabetic Federation (FDI) stated that almost $8.5 \%$ of the worldwide population is diabetic [2], with age group most affected being 20-79 years. The main reason for the epidemic of diabetes is the escalation of its causes [3]. Rapid sociocultural changes including lifestyle changes, aging, urbanization, changes in dietary habits, and physical inactivity are the major contributing factors [4]. Technical advances and modernization have made it possible to accomplish most of the daily activities in less time with minimum efforts using sophisticated instruments. Furthermore, substitution of low-calorie diets such as ragi with junk foods such as burger and pizzas lead to obesity which is one of the major predisposing factors of diabetes [5].

India is regarded as the diabetes capital as it has the highest prevalence of diabetes, accounting for more than $11.6 \%$ in the urban areas. Diabetes has been linked with excess body weight gain [6] and increased cardiovascular risk, where dyslipidemia and inflammation are the major contributing factors [7]. Several studies have reported lower health-related quality of life in patients with diabetes, that is further associated with the diabetic complications [8].

Cardiovascular disorders (CVD) are one of the major causes of morbidity and mortality in Type 2 diabetes [9]. C-reactive protein (CRP), an early biomarker of inflammation, has been shown to increase the risks of CVD in diabetic patients, as it is involved in the formation of atheromatous plaque [10]. However, it is yet to be clarified that whether the increase in the CRP is due to metabolic effects of obesity that promotes atherosclerosis or it merely signifies the inflammation persisting in the vessels affected in diabetes.

Several epidemiological as well as experimental studies in the past have shown that adiponectin, a major adipokine of adipocytes, have a beneficial role in glucose metabolism. It not only improves the insulin sensitivity but also lowers cardiovascular risks by suppressing the inflammatory mechanisms [11]. However, reports are conflicting whether the anti-inflammatory property possessed by adiponectin is apparent in diabetic patients or the effects of metabolic factors such as lipids and glycemia largely mediate them. Therefore, this study was planned to evaluate the relationship of adiponectin with CRP, so that the outcome of this study can serve as an aid in early prediction marker of cardiovascular complications in diabetes mellitus and improve the quality of living.

\section{METHODS}

It is a case-control study that included 25 healthy controls and 25 Type 2 diabetic patients. This study was carried out in the Department of Biochemistry, Santosh Medical College and Hospital, Ghaziabad. This study was carried out after ethical approval by the Institutional Ethical Committee. Every participant voluntarily participated, and written consent was taken from them. The information of patient was collected in prescribed format regarding age, gender, family history of diabetes, medication, smoking, etc.

\section{Inclusion criteria}

- Patients with Type 2 diabetes mellitus were included in this study. 


\section{Exclusion criteria}

- Patients with asthma, chronic obstructive pulmonary disease, inflammations, malignancies, STDs, hepatic diseases, cardiovascular, renal diseases, and gout and arthritis patients with Type 1 diabetes mellitus were excluded from the study.

Blood samples from both controls and patients were collected, and the serum was separated for the analysis of parameters such as adiponectin, hs-CRP, and fasting blood glucose. Serum adiponectin was analyzed by enzyme-linked immunosorbent assay while high sensitivity CRP (hsCRP) and glucose were estimated by kit based methods. The data were recorded and analyzed statistically using Student's t-test and Pearson's correlation coefficient.

\section{RESULTS}

A total of 25 Type 2 diabetic patients were included in the study of which $17(68 \%)$ were males and $8(32 \%)$ were females (Table 1). 25 age and sex-matched healthy controls were also included in the comparative study. The parameters studied in both control groups and diabetic groups were fasting blood sugar (FBS), serum adiponectin, and hs-CRP. The mean \pm standard deviation (SD) for serum adiponectin was higher in control group $(10.78 \pm 1.69)$ than in case of diabetic group $(5.64 \pm 1.78)$, and the difference of mean was statistically significant $(\mathrm{p}<0.05$, Table 2). The mean \pm SD for FBS and hs-CRP was higher in the diabetic group (FBS-158.2 \pm 32.72 and hs-CRP-3.97 \pm 1.54 ) compared to control group (FBS-80.52 \pm 9.72 and hs-CRP-1.27 \pm 0.75 ), and the difference was statistically significant $(\mathrm{p}<0.05$, Table 2$)$.

Adiponectin was negatively correlated with FBS, and the correlation was statistically significant $(r=-0.427, p<0.05)$ whereas when CRP was considered, it showed significant positive correlation with the FBS $(r=0.568, p<0.05)$. Adiponectin was negatively correlated with CRP, but the correlation was not statistically significant $(r=0.336, p>0.05$, Table 3). Table 4 shows the cardiovascular risk on the basis of the level of hs-CRP.

\section{DISCUSSION}

In the context of present scenario, prevention of diabetes has become one of the major health priority issues, as it not only requires long-term medical care to maintain the glycemic status but also increases the medical expenditure due to its life-threatening complications. Hence, in this study, we investigated the levels of serum adiponectin and hsCRP in Type 2 diabetic patients and compared with that of healthy controls. Results of this study support the hypothesis that diabetes is relatively associated with decreased adiponectin and increased CRP levels which can further lead to the development of CVD in future. Adiponectin, a major cytokine from adipose tissue which has been shown to reduce cardiovascular risk [11], was decreased in diabetic patients while CRP, a well-established biomarker for prediction of CVD was elevated. Table 4 shows the assessment of CVD risk based on the levels of hs-CRP.

Table 1: Patient distribution according to the gender

\begin{tabular}{ll}
\hline Gender & $\mathbf{n}(\%)$ \\
\hline Male & $17(68)$ \\
Female & $8(32)$ \\
\hline
\end{tabular}

Table 2: Comparison of adiponectin and hs-CRP among control group and diabetic group

\begin{tabular}{llll}
\hline Parameter & Control & Diabetic & p \\
\hline FBS (mg/dl) & $80.52 \pm 9.72$ & $158.2 \pm 32.72$ & $<0.05$ \\
Adiponectin (ng/ml) & $10.78 \pm 1.69$ & $5.64 \pm 1.78$ & $<0.05$ \\
Hs-CRP (mg/L) & $1.27 \pm 0.75$ & $3.97 \pm 1.54$ & $<0.05$ \\
\hline
\end{tabular}

hs-CRP: High sensitivity C-reactive protein, FBS: Fasting blood sugar
Adiponectin exhibits both insulin-sensitizing and anti-inflammatory effects, thus showing protective role by improving insulin secretion as well as impeding cytokine and fatty acid-mediated dysfunction of pancreatic $\beta$-cells [13]. Adiponectin through receptors 1 and 2 affects glucose metabolism [14]. It lowers blood sugar level by activating AMP-dependent protein kinase, which stimulates catabolism of both intracellular and extracellular energy sources (TAG and glucose, respectively) [15]. Adiponectin also lowers hepatic glucose synthesis by decreasing expression of the gluconeogenic enzyme [16].

Obesity is one of the major risk factors for diabetes as it is associated with insulin resistance that can further lead to the development of atherothrombotic disease in diabetic patients [17]. Through various experimental studies, it has been documented that there is reduced expression of adiponectin gene in obese subjects (which may be attributed to increased inflammatory cytokines and persistence of hypoxia in adipose tissue) or during the intake of high calorie whereas intake of energy within normal level does not impair expression of adiponectin gene and level of adiponectin in blood [18].

Thus, the exact underlying mechanism though is still to be clarified; it can be proposed that energy intake regulates adiponectin levels through the effects on adiponectin gene expression. In Type 2 diabetes, though there is a hyperglycemic state in the body, most of the cells cannot utilize glucose due to insulin resistance. Therefore, it can be hypothesized that hyperglycemia in diabetes mimics the increased calorie status of the body, that might lead to suppression of adiponectin gene leading to hypoadiponectinemia.

In our study too, hypoadiponectinemia was prevalent among the diabetic patients, and it was associated with increased cardiovascular risk which was determined by assessing CRP. The results of our study are supported by various studies conducted in the past. Kumuda et al. [11] and Hotta et al. [19] in their studies stated that hypoadiponectinemia was independently associated with the risk of CVD in diabetes, after consideration of other known risk factors. According to Mohan et al., hypoadiponectinemia is related to dyslipidemia which is one of the causative factors of coronary artery disease [20]. In a follow-up study conducted by Bahceci et al. [21], escalation of CRP indicated the increased the risk of a CAD. Similarly, in another study, it was documented that Type 2 diabetic men with CAD presented higher CRP levels in comparison to the diabetic men without CAD [22]. Statnick et al. quoted that expression of adiponectin gene is downregulated in obese diabetic patients than in non-diabetic and obese individuals [23]. Festa et al. suggested that people developing DM had higher baseline levels of hs-CRP than in controls [24], thus supporting our study.

Table 3: Correlation of adiponectin and hs-CRP with fasting blood glucose

\begin{tabular}{lll}
\hline Parameter & $\mathbf{r}$ & $\mathbf{p}$ \\
\hline FBS -Adiponectin & -0.427 & $<0.05$ \\
FBS - hs-CRP & 0.568 & $<0.05$ \\
Adiponectin-CRP & -0.336 & $>0.05$ \\
\hline
\end{tabular}

hs-CRP: High sensitivity C-reactive protein, FBS: Fasting blood sugar

Table 4: Assessment of cardiovascular risk according to CRP levels [12]

\begin{tabular}{ll}
\hline Hs-CRP & Cardiovascular risk \\
\hline 0 to $<1 \mathrm{mg} / \mathrm{L}$ & Low risk \\
1 to $3 \mathrm{mg} / \mathrm{L}$ & Intermediate risk \\
$>3$ to $10 \mathrm{mg} / \mathrm{L}$ & High risk \\
$>10 \mathrm{mg} / \mathrm{L}$ & Unspecific elevation \\
\hline
\end{tabular}

hs-CRP: High sensitivity C-reactive protein, FBS: Fasting blood sugar, CRP: C-reactive protein 
However, some studies have shown the results contrast to our findings. Obot et al. demonstrated no significant difference in the levels of serum adiponectin among diabetic patients and control [25]. Another study of Ljubic et al. also reported the similar result [26]. Furthermore, a crosssectional study of Streja et al. elucidated no association of hs-CRP with the complications of diabetes [27].

In this study, we also correlated adiponectin with CRP and both of them with FBS. We found a negative correlation of adiponectin with FBS and CRP while FBS and CRP were positively correlated. Our study was supported by the various previous studies. Wu et al. showed a positive correlation of hs-CRP with HbA1C and fasting blood glucose [28]. Venkatesh et al. [29] described an inverse correlation between plasma C-reactive protein and adiponectin, as well as a linear response between sickness severity and plasma adiponectin. The negative correlation between levels of C-reactive protein with adiponectin was also described by Ouchi et al. [30], and Engeli et al. [31]., and Krakoff et al. elucidated adiponectin to be an important connection between inflammation, obesity, and Type 2 diabetes [32].

Studies have also shown that antidiabetic drugs (like thiazolidinones) act by increasing levels of adiponectin. Recently adipoRN has been discovered which is suggested to be a novel therapeutic target for the treatment of diabetes associated with obesity [16]. However, further studies that facilitate a better understanding of the role of adiponectin in the reduction of Type 2 diabetes and associated CVDs are necessary.

\section{CONCLUSION}

According to the observation found in this study, it can be indicated that Type 2 diabetes is associated with decreased adiponectin and increased inflammatory markers such as hs-CRP. Since both the parameters are an important marker for CVD, fluctuations in their level can predispose the patients with type 2 diabetes toward the development of CVD in future. Although our study is very simplified, the outcomes of this study can further enlighten the physicians about the adverse effects of diabetes and hence encourage them for early detection and prevention of diabetes. As some results contradictory to ours have been found in past researches, our findings require elaboration through further studies. Since our study also possesses some limitations such as small sample size and use of single inflammatory marker, future study with larger samples and more promising tool to assess cardiovascular risk is suggested. Furthermore, studies with much focus on mechanistic prospective, showing the correlation of glycemic status, dyslipidemia and various other inflammatory markers that can predict the cardiovascular risk in diabetes are indicated. Besides that, modifications in lifestyle, as well as researches in therapeutic approaches that can increase adiponectin level, may be conducted to shed light on the alleviation of cardiovascular risks.

\section{CONFLICT OF INTEREST}

We have no financial interests regarding the manuscript, and we declare that there are no conflicts of interest.

\section{AUTHOR'S CONTRIBUTIONS}

Shailaza Shrestha: Experimental analysis and manuscript preparation; Dr. Preeti Sharma and Dr. Pradeep Kumar: Concept and study design; Rachana Sharma, Shivani Gupta, Tapan Mahapatra: Statistical analysis and manuscript revision.

\section{REFERENCES}

1. Tripathi GK, Sharm R, Verma, Sharma P, Kumar P. Biomarkers in serum, uric acid as a risk factor for Type 2 diabetes associated with hypertension. Asian J Pharm Clin Res 2016;9:216-8.

2. Sharma R, Sharma P, Pradeep K, Tripathi GK. A correlation between Glycosylated Hemoglobin and Lipid profile in Type-2 Diabetes mellitus with and without complications. Int J Contemp Med 2015;3:120-5.
3. Dongway AC, Faggad AS, Zaki HY, Abdalla BE. C-reactive protein is associated with low-density lipoprotein cholesterol and obesity in type 2 diabetic sudanese. Diabetes Metab Syndr Obes 2015;8:427-35.

4. Sharma P, Kumar P, Sharma R, Prakash SW. Assessment of cardiometabolic risk factors among local population of NCR. Asian J Pharm Clin Res 2017;10:211-3.

5. Shivashankar M, Mani D. A brief overview of diabetes. Int J Pharm Pharm Sci 2011;3 suppl 4:22-7.

6. Brunzell JD, Davidson M, Furberg CD. Lipoprotein management in patients with cardiometabolic risk: Consensus statement from the American Diabetes Association and the American College of Cardiology Foundation. Diabetes Care 2008;31:811-22.

7. Kumpatla S, Karuppiah K, Immaneni S, Muthukumaran P, Krishnan J, Narayanamoorthy SK, et al. Comparison of plasma adiponectin and certain inflammatory markers in angiographically proven coronary artery disease patients with and without diabetes-A study from India. Indian J Med Res 2014;139:841-50.

8. Andayani T, Ibrahim MI, Asdie AH. The association of diabetes related factor and quality of life in Type 2 diabetes mellitus. Int J Pharm Pharm Sci 2010;2:130-45.

9. Saleh DK, Koosha P, Sadeghi M, Sarrafzadegan N, Afshar RK, Boshtam M, et al. Predictive role of adiponectin and high-sensitivity C-reactive protein for prediction of cardiovascular event in an Iranian cohort study: The Isfahan Cohort Study. Arya Atheroscler 2016;12:132-7.

10. Kadowaki T, Yamauchi T, Kubota N, Hara K, Ueki K, Tobe K. Adiponectin and adiponectin receptors in insulin resistance, diabetes, and the metabolic syndrome. J Clin Invest 2006;116:1784-92.

11. Kumada M, Kihara S, Sumitsuji S, Kawamoto T, Matsumoto S, Ouchi N et al. Association of hypoadiponectinemia with coronary artery disease in men. Arterioscler Thromb Vasc Biol 2003;23:85-9.

12. Pfutzner A, Forst T. High-sensitivity C- reactive protein as cardiovascular risk marker in patients with Diabetes Mellitus. Diabetes Technol Ther 2006;8:28-36.

13. Rakatzi I, Mueller H, Ritzeler O, Tennagels N, Eckel J. Adiponectin counteracts cytokine- and fatty acid-induced apoptosis in the pancreatic beta-cell line INS-1. Diabetologia 2004;47:249-58.

14. Shreshtha S, Sharma P, Kumar P, Gupta G. Adiponectin: A review on physiological roles and associated disorders. Asian J Pharm Clin Res 2017;10:32-7

15. Hardie DG. Mini review: The AMP-activated protein kinase cascade: The key sensor of cellular energy status. Endocrinology 2003; 144:5179-83

16. Lee S, Kwak SB. Role of adiponectin in metabolic and cardiovascular disease. J Exe Rehabil 2014;10:54-9.

17. Schmidt MI, Duncan BB. Diabesity: An inflammatory metabolic condition. Clin Chem Lab Med 2003;41:1120-30.

18. Qiao L, Lee B, Kinney B, Yoo HS, Shao J. Energy intake and adiponectin gene expression. Am J Physiol Endocrinol Metab 2011;300:E809-16.

19. Hotta K, Funahashi T, Arita Y, Takahashi M, Matsuda M, Okamoto Y et al. Plasma concentrations of a novel, adipose-specific protein, adiponectin, in Type 2 diabetic patients. Arterioscler Thromb Vasc Biol 2000;20:1595-9.

20. Mohan V, Deepa R, Pradeepa R, Vimaleswaran KS, Mohan A, Velmurugan $\mathrm{K}$ et al. Association of low adiponectin levels with the metabolic syndrome - the Chennai Urban Rural Epidemiology Study (CURES-4). Metabolism 2005;54:476-81.

21. Pai JK, Pischon T, Ma J, Manson JE, Hankinson SE, Joshipura K et al. Inflammatory markers and the risk of coronary heart disease in men and women. N Engl J Med 2004;351:2599-610.

22. Bahceci M, Tuzcu A, Ogun C, Canoruc N, Iltimur K, Aslan C. Is serum $\mathrm{C}$-reactive protein concentration correlated with $\mathrm{HbA} 1 \mathrm{c}$ and insulin resistance in Type 2 diabetic men with or without coronary heart disease? J Endocrinol Invest 2005;28:145-50.

23. Statnick MA, Beavers LS, Conner LJ, Corominola H, Johnson D, Hammond CD et al. Decreased expression of apM1 in omental and subcutaneous adipose tissue of humans with type 2 diabetes. Int J Exp Diabetes Res 2000;1:81-8

24. Festa A, Agostino RD, Howard G, Mykkanen L, Tracy RP, Haffner SM. Chronic subclinical inflammation as part of the insulin resistance syndrome: The insulin resistance atherosclerosis study (IRAS). Circulation 2000;102:42-7.

25. Obot SA, Usoro CA, Anyanwu AC, Egbe ER, Ekott JU, Usoro AJ. Adiponectin and cardiovascular risk factors in relation with glycemic control in type 2 diabetics. Int J Res Med Sci 2013;1:563-70.

26. Ljubic S, Boras J, Jazbec A, Lovrencic MV, Vidjak V, Erzen DJ et al. Adiponectin has different mechanisms in Type 1 and Type 2 diabetes 
with C-peptide link. Clin Invest Med 2009;32:E271-9.

27. Streja D, Cressey P, Rabkin SW. Associations between inflammatory markers, traditional risk factors, and complications in patients with Type 2 diabetes mellitus. J Diabetes Complications 2003;17:120-7.

28. Wu T, Dorn JP, Donahue RP, Sempos CT, Trevisan M. Associations of serum C-reactive protein with fasting insulin, glucose, and glycosylated hemoglobin: The third national health and nutrition examination survey. Am J Epidemiol 2000;155:65-71

29. Venkatesh B, Hickman I, Nisbet J, Cohen J, Prins J. Changes in serum adiponectin concentrations in critical illness: A preliminary investigation. Crit Care 2009;13:R105.

30. Ouchi N, Kihara S, Funahashi T, Nakamura T, Nishida M, Kumada M et al. Reciprocal association of C-reactive protein with adiponectin in blood stream and adipose tissue. Circulation 2003;107:671-4.

31. Engeli S, Feldpausch M, Gorzelniak K, Hartwig F, Heintze U, Janke J et al. Association between adiponectin and mediators of inflammation in obese women. Diabetes 2003;52:942-7.

32. Krakoff J, Funahashi T, Stehouwer CD, Schalkwijk CG, Tanaka S, Matsuzawa $\mathrm{Y}$ et al. Inflammatory markers, adiponectin, and risk of Type 2 diabetes in the Pima Indian. Diabetes Care 2003;26:1745-51. 